\title{
Growth evaluation: parent and child specific height standards
}

\author{
R SORVA, E-M TOLPPANEN, S LANKINEN, AND J PERHEENTUPA \\ Children's Hospital, University of Helsinki, Finland
}

SUMmARY Data on the growth of 1063 children and their parents were analysed. Of the variation in height at prepuberty about $20 \%$, and of the final height $30-46 \%$, were explained by the variation in parental heights; the children's own height at the age of 1.0 year increased the proportion explained to half. Two equations were developed for increasing the accuracy of the evaluation of growth. One defines parent specific mean height standard deviation score, and the other includes the parents' heights and the child's height at the age of 1.0 year and defines expected standard deviation score for height. These equations are easy to use if they are converted to nomograms.

The accuracy of the evaluation of growth could be improved by the use of parent and child specific standards instead of population standards. Tanner $e t$ al published parent specific standards, ${ }^{1}$ but their use requires a special chart and their validity for other populations is unknown.

We have analysed the longitudinal growth and maturation of 1063 Finnish children and their parents, and present practical new methods for obtaining parent specific height standard deviation scores, and for including the child's height at the age of 1.0 year in the assessment of growth.

\section{Subjects and methods}

All heights and weights recorded in child health
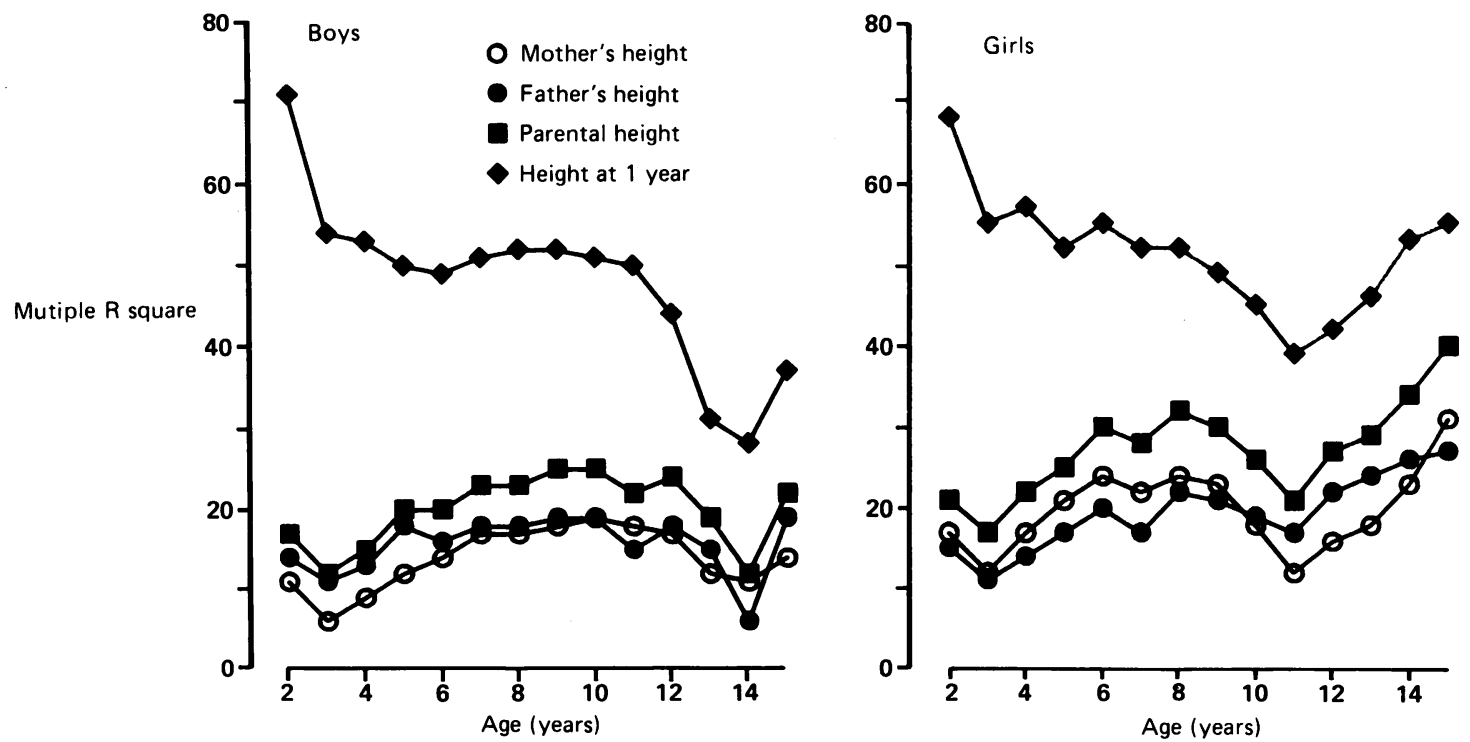

Fig 1 The proportion of the variation (Rsquare in multiple regression) in height at different ages explained by the heights of parents and children's own heights at the age of 1.0 year for 231 boys and 231 girls. 
centres and schools were collected from birth (in 1959-1961) until 1978 for 544 healthy boys. and 519 girls: 412 boys and 351 girls from the city of Helsinki and 132 boys and 168 girls from eastern Finland. The sample is representative of the whole social class structure. The population of Helsinki is a mixed one, originating from all areas of Finland. The boys were an unselected group of military conscripts; the girls were secondary school graduates. Eastern Finland was selected for the second sample as the most likely area to show any difference from the mixed population. Because there was no significant difference between the two samples they were pooled and considered as being representative of the whole population.

We evaluated height as standard deviation scores, using linear interpolation to obtain the height at each full year from actual measurements made within half a year. The latest height available,

Table 1 Percentages of the variations in final height in 231 boys and 231 girls ( $R$ square in multiple regression analysis) explained by variation in the child's own heights at full years 0 to 5 and parental heights

\begin{tabular}{lll}
\hline & Boys & Girls \\
\hline Birth height & 10 & 14 \\
Height at 1 year & 35 & 36 \\
Height at 2 years & 38 & 52 \\
Height at 3 years & 33 & 45 \\
Height at 4 years & 50 & 54 \\
Height at 5 years & 57 & 63 \\
Father's height & 22 & 32 \\
Mother's height & 24 & 35 \\
Both parents' heights & 30 & 46 \\
Both parents' heights plus child's birth height & 35 & 52 \\
Both parents' heights plus child's height & 53 & 57 \\
at 1·0 year & & \\
Both parents' heights plus child's height & 60 & 72 \\
at 5.0 years &
\end{tabular}

recorded after the age of $17 \cdot 0$ for girls and 18.0 years for boys, was regarded as the final height, provided that the increment during the preceding year had been less than $1.0 \mathrm{~cm}$. The age just before height velocity began to increase ('take off') ${ }^{2}$ and the age at the peak height velocity during puberty were determined individually by smoothing individual growth velocity data by a cubic square spline function. ${ }^{3}$

From a questionnaire we ascertained the heights of the parents, the ages at menarche of the girls and their mothers, and the timing of growth and maturation in the fathers (early, average, or late growth spurt compared with peers). Virtually all men have their height at the age of 20 recorded in their military passport. If no accurate height measurement was on record the parents were asked to have their heights measured at the local health centre.

For statistical evaluation we used simple and multiple linear regression analysis. ${ }^{4}$

\section{Results}

We calculated the proportion of the variation by

Table 3 The differences $(\mathrm{cm})$ between the final height measured and the adult $\mathrm{cm}$ values corresponding to the height standard deviation scores determined by the three equations (table 2)

\begin{tabular}{lccc}
\hline & \multicolumn{3}{c}{ Difference } \\
\cline { 3 - 4 } & No & Mean & $S D$ \\
\hline Boys: & & & \\
SDS 1 & 474 & $-0 \cdot 2$ & $5 \cdot 3$ \\
SDS 2 & 474 & $-0 \cdot 8$ & $5 \cdot 3$ \\
SDS 3 & 335 & $0 \cdot 4$ & $4 \cdot 3$ \\
& & & \\
Girls: & & & $4 \cdot 8$ \\
SDS 1 & 466 & $0 \cdot 1$ & $4 \cdot 9$ \\
SDS 2 & 466 & -0.4 & $3 \cdot 7$ \\
SDS 3 & 301 & $-0 \cdot 2$ & \\
\hline
\end{tabular}

Table 2 Equations for determination of parent specific mean height standard deviation scores (SDS 1 and SDS 2) and parent and child specific expected height standard deviation scores (SDS 3). The equations for

SDS 1 and SDS 3 are based on the present data for 335 boys and 301 girls. The equation for SDS 2 is: midparental height minus population mean midparental height, divided by 10 (the product of 5 and 2, where 5 is the approximate value of height $S D$ for adults. ${ }^{5} \mathrm{H}=$ height $(\mathrm{cm}), \mathrm{H} 1 \cdot 0=$ height at age 1.0 year. Values of constants are given below.

$\mathrm{SDS}_{1}=\mathrm{X}_{1} \times \mathrm{H}$ of father $+\mathrm{Y}_{1} \times \mathrm{H}$ of mother $+\mathrm{Z}_{1}$

$\mathrm{SDS}_{2}=((\mathrm{H}$ of father $+\mathrm{H}$ of mother $) \div 2-170) \div 10$.

$\mathrm{SDS}_{3}=\mathrm{X}_{3} \times \mathrm{H}$ of father $+\mathrm{Y}_{3} \times \mathrm{H}$ of mother $+\mathrm{V} \times \mathrm{H} 1 \cdot 0+\mathrm{Z}_{3}$

\begin{tabular}{llllllll}
\hline & $X_{I}$ & $Y_{I}$ & $Z_{I}$ & $X_{3}$ & $Y_{3}$ & $V$ & $Z_{3}$ \\
\hline Boys & 0.0607 & 0.0638 & $-21 \cdot 0$ & 0.0423 & 0.0526 & $0 \cdot 172$ & $-29 \cdot 0$ \\
Girls & 0.0619 & 0.0765 & $-23 \cdot 3$ & 0.0420 & 0.0552 & $0 \cdot 170$ & $-29 \cdot 2$ \\
Both & 0.0611 & 0.0703 & $-22 \cdot 1$ & 0.0423 & 0.0542 & $0 \cdot 166$ & -28.9 \\
\hline
\end{tabular}


multiple regression analysis (\%, multiple $\mathbf{R}$ square) in the heights of children explained by the variation in the heights of their parents. Before puberty, at the ages of 2.0 to 13.0 years for boys and 2.0 to 11.0 years in girls, $6-24 \%$ of the variation in the children's height was explained by the variation in height of the fathers or the mothers, and $15-32 \%$ by the variation in height of both parents (fig 1). These proportions were higher for girls than for boys. Inclusion in the analysis of the children's own
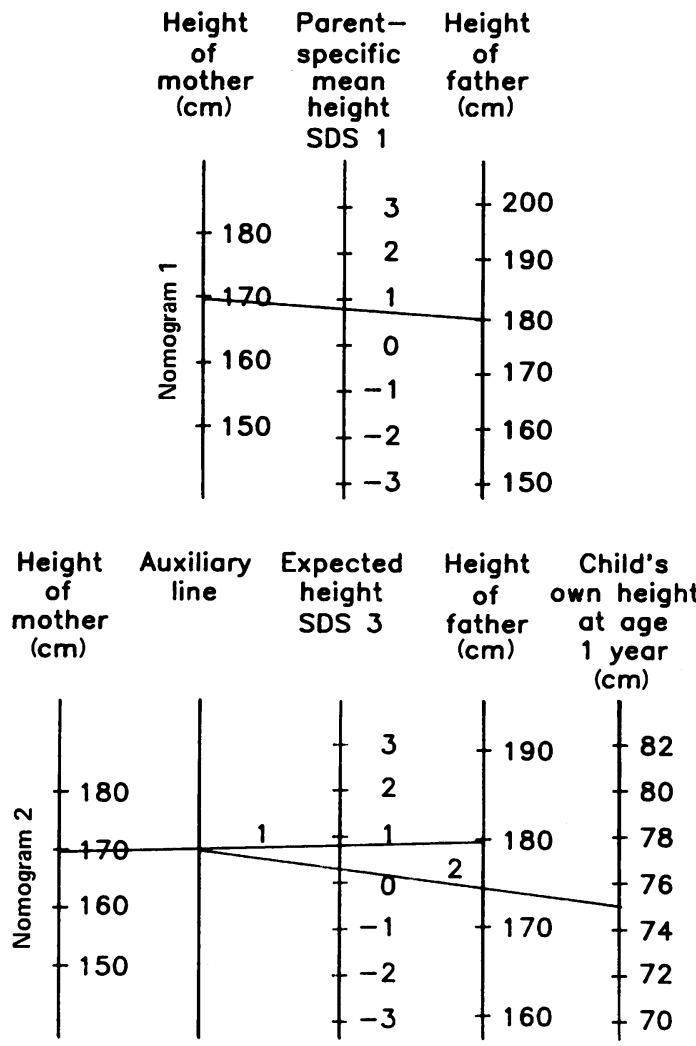

Fig2 Nomogramsforprediction of height (for equations see table 2). Nomogram 1: draw aline to connect the heights ofmother and father. The cut off point indicates the parent specific mean heightstandard deviation score (SDS1). Nomogram 2: first draw line 1 to connect the heights of mother and father. Then draw line 2 to connect the child's own height at the age of 1.0 year with the cut off point of line 1 and the auxiliary line. The cut off point of line 2 indicates the child specific expected height standard deviationscore (SDS3). Example: if the height of the father is $180 \mathrm{~cm}$, the height of the mother $170 \mathrm{~cm}$, and the child's own height at age 1.0 year $75 \mathrm{~cm}$, then parent specific mean height standard deviationscore is +0.8 and child specific expected height standard deviationscore 3 is $+0 \cdot 4$. heights at the age of 1.0 year improved the proportions explained (fig 1).

We made a similar calculation for the proportion of the variation in final height explained by the variation in birth length or height at later ages, or both (table 1). The older the age included, the higher was the proportion explained. Of the variation in final height, $30 \%$ for boys and $46 \%$ for girls were explained by the variation in the heights of both parents. These proportions improved to $53 \%$ and $57 \%$, respectively, after addition of the children's own heights at the age of 1.0 year.

We developed two equations to improve the accuracy of evaluation of height (table 2). The first includes parental heights and defines parent specific mean standard deviation scores. The second also includes the child's height at the age of 1.0 year and defines the expected standard deviation score. We compared these with a simple, easy to memorise equation according to which the parent specific mean standard deviation score is half the mean standard deviation score of the parents. ${ }^{5}$ On average the difference between the final height measured and that expected from these equations was small (table 3 ). In practice, the two new equations are converted to nomograms (fig 2).

The mean (SD) age at menarche of the mother$14.1(1.6)$ years-correlated positively with the daughter's age at menarche-12.9 (1.2) years$(\mathrm{n}=519, \mathrm{r}=0 \cdot 28, \mathrm{p}<0 \cdot 001)$ - her age at 'take off'$8 \cdot 5(1 \cdot 1)$ years, and her age at peak height velocity$11.4(1.1)$ years $(n=179, r=0.16, p<0.05$, in both cases). The ages at 'take off' and at peak height velocity were lower for the children whose fathers had reached their final height early (table 4).

\section{Discussion}

About $20 \%$ of the variation in height at any

Table 4 Father and child relationships in the timing of maturation

\begin{tabular}{|c|c|c|c|}
\hline & \multicolumn{3}{|c|}{ Timing of father's puberty } \\
\hline & Early & Average & Late \\
\hline \multirow{3}{*}{$\begin{array}{l}\text { Boys: } \\
\text { Age at take off } \\
\text { Age at peak } \\
\text { height velocity }\end{array}$} & $(n=27)$ & $(n=178)$ & $(n=47)$ \\
\hline & $9 \cdot 4(1 \cdot 3)$ & $9.7(1.4)$ & $9 \cdot 8(1 \cdot 3)$ \\
\hline & $12 \cdot 8(1 \cdot 5)^{* *}$ & $13 \cdot 6(1 \cdot 1)$ & $13 \cdot 7(1 \cdot 0)$ \\
\hline \multirow{3}{*}{$\begin{array}{l}\text { Girls: } \\
\text { Age at take off } \\
\text { Age at peak } \\
\text { height velocity }\end{array}$} & $(n=16)$ & $(n=124)$ & $(n=31)$ \\
\hline & $8 \cdot 1(0.9)$ & $8.7(1.3)$ & $8.3(0 \cdot 8)$ \\
\hline & $10.9(0.9)$ & $11 \cdot 5(1 \cdot 1)$ & $11 \cdot 3(1.4)$ \\
\hline
\end{tabular}

Values are mean (SD) years, ${ }^{* *} \mathrm{p}<0.01$. 
prepubertal age, and $30-46 \%$ of the variation in final height, was explained by the variation in parental heights. The inclusion of the children's own heights at the age of 1.0 year increased the proportion explained to $50 \%$. Tanner et al reported that the percentage of adult variance that could be accounted for by the data about heights at the ages of $0,1,2,3,4$, and 5 years was $67 \%$ in males and $64 \%$ in females. ${ }^{6}$ He concluded that the principal determinant of the size of a newborn baby is the prenatal environment, which depends on hereditary characteristics of the mother, the influence of the inherent growth characteristics of the child appears only later. ${ }^{6} \mathrm{He}$ considered that adult height can be predicted equally well at the ages of 3,4 , and 5 years.

Tanner et al published a chart for calculating height standards that allowed for the parents' heights at the ages of 2 to 9 years. ${ }^{1}$ In this chart the standards are in the form of a regression line (child's height against midparental height) with standard deviations calculated from the average sex specific standard deviation of the general population multiplied by $0 \cdot 87$.

Tanner also described a 'target height method' in which a child's predicted final height is compared with a target range of height that can be expected from the heights of the parents. ${ }^{7}$ The centre of the target range is midparental height plus $6.5 \mathrm{~cm}$ for boys and midparental height minus $6.5 \mathrm{~cm}$ for girls $(6.5 \mathrm{~cm}$ being half the mean sex difference in adult height). The target range is two standard deviations below and above this figure, and the standard deviation equals the sex specific standard deviation of the general population multiplied by $0.77 .^{7}$ Tanner's two methods differ essentially from each other, the first implies that the mean height standard deviation score of children is half the mean score of the parents (our simple equation 2), but the second method takes the straight mean standard deviation score of the parents as being the mean score of the children.

Our data may be criticised for lack of accuracy because the measurements were made within the primary health care system, and especially because the timing of parental maturation was based on recollection. Obtaining accurate longitudinal data would require almost two decades and-more importantly -it is with the same kind of less than perfect data that child health surveillance will always have to deal when monitoring children's growth. The Finnish child health surveillance system has a long tradition of measuring every child annually. We believe that our data are the best possible in the absence of longitudinal measurements by anthropometrists.
We calculated parent specific mean height standard deviation scores and the child specific expected standard deviation score. The latter can be used for detecting an acquired growth disorder in children whose growth during the first year of life is believed to be normal. We chose the age of 1 year instead of the ages of 2 or 3 years, though the latter correlated better with the final height. We did this because we wanted to minimise the risk that an acquired nondiagnosed disease might already have influenced the height used in the prediction, and also to maximise the age range at which the prediction could be used. These equations may be used easily as nomograms. The standard deviations of the differences between the measured final heights and those expected from these two equations were 4.3 to $5.3 \mathrm{~cm}$ for boys and 3.7 to $4.9 \mathrm{~cm}$ for girls, which is clearly less than the standard deviations of final height in the general population $(6.0 \mathrm{~cm}$ for men and $5.4 \mathrm{~cm}$ for women). Interestingly, the simple calculation of parent specific height standard deviation score by taking mean parental height $(\mathrm{cm})$, subtracting 170 and dividing by 10 , proved to be as accurate as the more complex equation developed from our present data. The simple equation has been derived ${ }^{5}$ from the complex chart of Tanner et al. ${ }^{1}$ These equations are not proposed to predict final height, but to improve detection of abnormal growth in child health surveillance. A child's height standard deviation score at different ages should be compared with the expected parent specific and child specific score. We have recommended that if a child's actual standard deviation score differs by more than 2.0 from the parent specific mean score, or more than 1.5 from the expected score, this should arouse suspicion of a growth disorder. We have incorporated the parent and child specific height standard deviation scores into a 'growth screen'-a set of rules defining (for child health surveillance) which kinds of growth are acceptable and which kinds call for the attention of a specialist. This screen also includes limits for changes in height standard deviation scores. ${ }^{89}$

The ages at 'take off' and at peak height velocity were similar in our series to these of Preece and Heinrich, who obtained them using mathematical models of individual growth curves. ${ }^{2}$ They were about 1 year lower than in the study of Largo et al, in which velocity curves were analysed using smoothing spline functions, as in our study. ${ }^{10}$

The ages at menarche of the daughters and mothers were positively related in our study, as in another. ${ }^{11}$ We found similar correlations between the age at menarche of the mothers and the ages at 'take off' and at the peak height velocity of the daughters. The rough estimate of timing of maturation of the fathers was also positively correlated with 
that of the children, especially the sons. We have completed our growth screen with a puberty screen in which the screening limits are defined by $95 \%$ confidence intervals of the population for pubertal acceleration of growth, and the ages at start of growth of breasts, male genitals, and pubic hair. We consider that if the timing of maturation of one or other parent has deviated from the population mean by at least 1 year, we accept that the timing of maturation of the child may exceed the screening limits by at most 1 year in the same direction. By this we mean that there is no need for diagnostic evaluation. Young people who differ clearly in timing of maturation from their peers, however, need information about why they are different, and what will be the course of their development.

In conclusion, we have developed rules for application of information of the parents' heights and maturation history to the evaluation of the growth and maturation of children. Our rules lack scientific accuracy, but we prefer using them to having no rules at all to offer for child health surveillance.

This study was supported by the Foundation for Paediatric Research, the Medical Research Council of the Academy of Finland, National Board of Health, the Paulo Foundation, and the Finnish Cultural Foundation, Helsinki, Finland.

\section{References}

${ }^{1}$ Tanner JM, Goldstein H, Whitehouse RH. Standards for children's height at ages 2-9 years allowing for height of parents. Arch Dis Child 1970;45:755-62.

2 Preece MA, Heinrich I. Mathematical modelling of individual growth curves. Br Med Bull 1981;37:247-52.

3 De Boor C. A practical guide to splines. Applied mathematical sciences. New York: Springer Verlag, 1974.

${ }^{4}$ Dixon WJ. BMDP statistical software. Berkeley: University California Press, 1981

5 Perheentupa J. Lapsuuden ja nuoruuden endokrinologiaa. In: Lamberg B-A, Nikkilä E, Pelkonen R, eds. Kliininen endokrinologia. 2nd ed. Helsinki: Duodecim, 1984:514-94.

6 Tanner JM, Healy MJR, Lockhart RD, Mackëzie JD, Whitehouse RH. Aberdeen growth study. 1. The prediction of adult body measurements from measurements taken each year from birth to 5 years. Arch Dis Child 1956;31:372-81.

7 Tanner JM. Use and abuse of growth standards. In: Falkner F, Tanner JM, eds. Human growth. Vol III. 2nd ed. New York: Plenum Press, 1986.

${ }^{8}$ Sorva R, Tolppanen E-M, Lankinen S, Perheentupa J. Variation of postinfantile growth in height and weight. An analysis of 2000 children. Acta Paediatr Scand (in press).

9 Sorva R, Tolppanen E-M, Perheentupa J. Variation of growth in length and weight in infancy. Acta Paediatr Scand (in press).

${ }^{10}$ Largo RH, Gasser TH, Prader A, Stuetzle W, Huber PJ. Analysis of the adolescent growth spurt using smoothing spline functions. Ann Hum Biol 1978;5:421-34.

11 Kantero R-L, Widholm O. A statistical analysis of the menstrual patterns of 8000 Finnish girls and their mothers. Acta Obstet Gynecol Scand 1971;30:1-35.

Correspondence to Dr R Sorva, Rakuunantie 9 B 21, 00330 Helsinki, Finland.

Accepted 7 February 1989 